

\title{
A GUERRA CIVIL ESPANHOLA E A AMÉRICA LATINA
}

\author{
Organização:
}

Horacio Gutiérrez

Vivian Urquidi

Margarida Nepomuceno

Mayra Coan Lago

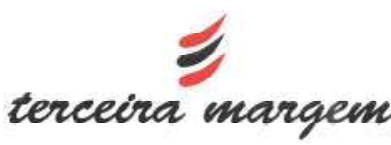


Copyright ( 2018 dos organizadores e autores dos textos

\section{Catalogação na Publicação Serviço de Biblioteca e Documentação}

Escola de Comunicações e Artes da Universidade de São Paulo

G934g A guerra civil espanhola e a América Latina [recurso eletrônico] / Horacio Gutiérrez.. [et al.] (Organizadores) - São Paulo : PROLAMEPAL/USP : CEDHAL/USP: ECA-USP, Terceira Margem, 2018. $477 \mathrm{p}$.

\section{ISBN 978-85-7921-101-0}

1. Relações internacionais - América Latina 2. Relações internacionais -Espanha 3. Relações diplomáticas - América Latina 4. Relações diplomáticas - Espanha 5. Guerra Civil Espanhola I.

Gutiérrez, Horacio.

CDD 21.ed. - 303.4828

Elaborado por: Sarah Lorenzon Ferreira CRB-8/6888 


\section{Organizadores}

Horacio Gutiérrez

Vivian Urquidi

Margarida Nepomuceno

Mayra Coan Lago

\section{Instituições e grupos de pesquisa}

Programa de Pós-Graduação Integração da América Latina - PROLAM/USP

Encontro de Pesquisadores da América Latina - PROLAM-EPAL/USP

Centro de Estudos de Demografia Histórica da América Latina - CEDHAL/ USP

\section{Instituições apoiadoras}

Escola de Comunicações e Artes da Universidade de São Paulo - ECA/USP

\section{Informações gráficas}

Capa: Camila Antunes Madeira da Silva

Imagens da capa: "Segundo año triunfal, noviembre 1937"; "Segundo año triunfal, enero 1938"; e "Jamás, enero 1938" da Revista Arriba España (números I e III, anos 1937 e 1938). "La Guerra Civil" e "La Guerra Civil en España", Revista Caras y Caretas (número 1993, 1936); "Niño Español Asesinado"; "El"; "Ella"; "Han pasado las alas negras de la invasión dejando en su pueblo su "civilización"" da Revista Facetas de Actualidad Española (ano I, números 5 e 12,1938). "Chile y el derecho de asilo; Españoles incorporados al progreso de Chile agradecen al C.Ch.A.R.E; Favorecen a Chile inmigrantes españoles; Los refugiados españoles", Semanario del Comité Chileno (C.Ch.A.R.E.) de Ayuda a los Refugiados Españoles. Santiago: El Comité, 1939, n 4, 6-8, 10, (1939). As revistas estão disponíveis online na Hemeroteca Digital da Biblioteca Nacional de España e os recortes do Semanario no site Memoria Chilena.

\section{Revisão}

Horacio Gutiérrez

Vivian Urquidi

Margarida Nepomuceno

Mayra Coan Lago 
ISBN: 978-85-7921-101-0

DOI: $10.29327 / 5.2908$

E-book gratuito e de livre circulação.

Proibida a venda e seu uso com fins comerciais.

Projeto e Edição Gráfica:

Editora Terceira Margem

PROLAM - Programa de Pós-Graduação Integração da América Latina

Av. Prof. Lucio Martins Rodrigues, $443-1^{\circ}$ andar - Sala 116 - Cid. Universitária São Paulo - 05508-080 - Brasil

CEDHAL - Centro de Estudos de Demografia Histórica da América Latina

Faculdade de Filosofia, Letras e Ciências Humanas - Universidade de São Paulo

Av. Prof. Lineu Prestes, 338 - Cidade Universitária

São Paulo - 05508-080 - Brasil

\section{Conselho Editorial Editora Terceira Margem}

Dilma de Melo Silva

Horacio Gutiérrez

Ilana Peliciari Rocha Joana de Fátima Rodrigues Juliane Caravieri Martins Lalada Dalglish

Lisbeth Rebolo Gonçalves

Marcelo Santos Rodrigues

Maria da Conceição Silva

Simone de Rocha Abreu

Vivian Urquidi
Universidade de São Paulo

Universidade de São Paulo

Universidade Federal do Triângulo Mineiro

Universidade Federal de São Paulo

Universidade Federal de Uberlândia

Universidade Estadual Paulista

Universidade de São Paulo

Universidade Federal do Tocantins

Universidade Federal de Goiás

Universidade Federal de Mato Grosso do Sul

Universidade de São Paulo 


\section{Sumário}

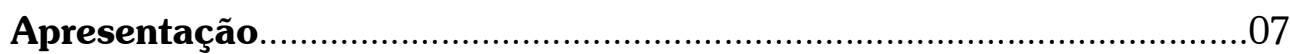

O Brasil na trama do conflito: sociedade e governo diante da Guerra Civil da Espanha (1936-1939)

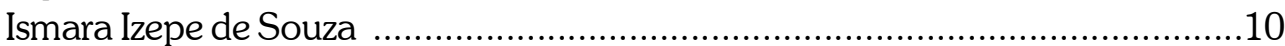

A Guerra Civil Espanhola e a solidariedade antifascista brasileira

Thaís Battibugli

Brigadistas internacionales: brasileños en el frente durante la Guerra Civil Española

Esther Gambi Giménez

Cruzando fronteiras: as experiências de guerra dos voluntários paraguaios e brasileiros durante o conflito civil espanhol (1936-1939) retratadas no álbum fotográfico de Víctor Martínez

Marco Antônio Machado Lima Pereira \& Gabriela Dalla-Corte Caballero

Cuando ellos ganaron. El triunfo de los eurocéntricos y el mito de los voluntarios latinoamericanos en la Guerra Civil Española

Jerónimo Boragina

Cerrando puertas: la postura del gobierno argentino frente al exilio político español y la movilización social pro-republicana en el período de entreguerras

Lidia Bocanegra Barbecho 107

Exilios epistolares. La Asociación de Padres y Familiares de los niños españoles refugiados en México (1937-1940)

Verónica Sierra Blas

iArriba España!: Brasileiros no exército de Franco

Eliane Venturini

La Oficina de Prensa y Propaganda de la Representación del General Franco en la Argentina y su labor propagandística durante la Guerra Civil Española (19361939)

Alejandra Noemí Ferreyra 167

La persecución franquista en Argentina y Chile (1939-1945): procedimientos y herramientas

Elena Romero 188

Guerra Civil Espanhola e o pensamento conservador latino-americano Maria Antonia Dias Martins 
Entre la derrota y el exilio. Dos experiencias latinoamericanas

Antolín Sánchez Cuervo

1936-1939: Divisiones y acuerdos en el campo cultural en Uruguay

Pablo Rocca

O assassinato que uniu dois continentes. A obra e o fuzilamento de Lorca, da Guerra Civil Espanhola para a América

Syntia Alves

Repercusión de los intelectuales españoles desterrados en la formación del Grupo Orígenes en Cuba

Jesús J. Barquet.

Os poetas de "Madre España": Guerra Civil Espanhola e frentismo cultural no Partido Comunista do Chile

Carine Dalmás

Espanhóis na América Latina: refúgio, resistência e arte

Margarida Nepomuceno

Un petit con no México

Yanet Aguilera

Gustavo Cochet: Um compromisso gravado

Margareth Santos

As marcas do impacto. Narrativas e representações da Guerra Civil Espanhola

Maria Luiza Tucci Carneiro 366

A Guerra Civil Espanhola chega ao Brasil: trajetórias interrompidas pelo conflito Juliana Sada \& Rodrigo Valente

Pelos caminhos de um ex-combatente da Guerra Civil Espanhola: testemunho, experiências e resistências na cidade de São Paulo (década de 1950)

Geny Brillas Tomanik

Anexos

Arquivos e fontes online sobre a Guerra Civil Espanhola e a América Latina

Mayra Coan Lago \& André Luiz Lanza

Niños de la guerra: Solidaridad uruguaya con la República Española (1936-1939)

Claudia Romero Duarte

Sobre os autores e organizadores 


\title{
Cerrando puertas: la postura del gobierno argentino frente al exilio político español y la movilización social pro-republicana en el período de entreguerras ${ }^{1}$.
}

\author{
Lidia Bocanegra Barbecho
}

Durante el conflicto español, 1936-1939, el gobierno argentino estuvo bajo la presidencia conservadora de Agustín Pedro Justo (1932-1938) y Roberto Marcelino Ortiz (1938-1940) quienes, junto con el Comité Ejecutivo de turno, se resguardaron detrás de una posición de prescindencia con respecto al conflicto de España. Esta actitud contrastaba fuertemente con la opinión social argentina y la oposición política, quienes a grandes rasgos solicitaban el rechazo del Comité de No Intervención, ayuda material al gobierno de la República y, por último, acogida para los miles de refugiados republicanos ubicados en los campos de concentración franceses peninsulares y coloniales.

La población, con fuerte presencia de la colonia inmigrante española, aunque polarizada fue mayoritariamente pro-republicana; junto a ella estaban los grupos sindicales, gremiales y partidos políticos de la oposición quienes fueron apoyados por una intelectualidad periodística cuyas plumas incansablemente escribieron a favor del gobierno leal de la República. Tanto unos como otros formaban parte de la corriente cultural antifascista de la década de 1930 caracterizada por una defensa del sistema republicano, de la política inmigratoria no restrictiva y la exaltación de la U.R.S.S. como modelo de desarrollo social, etc ${ }^{2}$.

La Cancillería Argentina, formada por conservadores, militares y oligárquicos terratenientes $e$ industriales, fue muy proclive a mantenerse neutral con respecto al conflicto español en donde veía un auge de las ideas marxistas. De esta manera, la izquierda argentina, hija de la cultura-política inmigrante italiana y española como colonias mayoritarias, fue perseguida, clausurada y censurada ya durante los gobiernos predecesores de R.M. Ortiz, de

1. Este texto recopila una serie de investigaciones cuyos resultados ya han sido publicados previamente por la autora. Véase listado bibliográfico.

2. Para una mayor información acerca de la corriente cultural antifascista de la década de 1930 en Argentina véase Ricardo Pasolini (2004). 
corte militar y fascista y amparados igualmente en el fraude electoral: generales Félix José Uriburu y Agustín P. Justo.

De la prescindencia, agosto 1936, se pasó rápidamente al reconocimiento de jure del gobierno franquista el 27 de febrero de 1939. Estudios al respecto remarcan la importancia del rol desempeñado por Inglaterra en dicha toma de decisión al tratarse del primer cliente de Argentina y siendo, a su vez, el principal artífice del Comité de No Intervención. El mantener una buena relación con dicho País era esencial a fin de salvaguardar los beneficios económicos que Gran Bretaña comercialmente le ofrecía. Cabe destacarse que, al igual que la España franquista, el gobierno argentino solamente compartía el odio al comunismo pero a diferencia de él preferían el sistema parlamentario al autoritarismo de corte fascista, o sea: las dictaduras (Quijada, 1991:24-26, 35). Si bien había en el poder algunos partidarios de las ideas filo-nazi-fascistas, éstas quedaron relegadas a la periferia del poder por parte de Justo y Ortiz; sin embargo, fueron muy potentes en términos discursivos y en la esfera pública a través de órganos de prensa tales como Bandera Argentina, Crisol, Fronda y Clarinada.

Ya fueran intereses económicos, matices ideológicos dentro del propio poder, así como la presión social con respecto a la causa republicana, lo cierto es que condicionaron la conducta del gobierno argentino con respecto al conflicto español, declarándose prescindente en un inicio y neutral, después. Se trató de una política proteccionista que descansaba en una posición neutralista no solamente con el conflicto español, sino también con la II Guerra Mundial y que determinó, indudablemente, sus actuaciones en política interna y externa ${ }^{3}$.

\section{La sociedad responde: el socorro pro-republicano}

Pese a declararse Argentina un Estado neutral, pese a inhibir los partidos y sindicatos de izquierda, la sociedad argentina, politizada o no, respondió desafiando al gobierno a través de las ayudas humanitarias pro-republicanas. Varios son los factores que condicionaron esa conducta: por un lado, la conexión cultural-sanguínea de la propia colonia inmigrante española, núcleo del movimiento solidario y numéricamente mayoritaria dentro de aquel mosaico

\footnotetext{
3. Estaban a favor de la neutralidad con respecto a la Segunda Guerra Mundial los sectores dirigentes tradicionales, núcleos pro-Eje en las Fuerzas Armadas, grupos civiles del nacionalismo católico, así como los nacionalistas populares (Fuerza de Orientación Radical de la Joven Argentina -FORJA, Sabattini en la UCR). En contra se hallaban los conservadores reformistas, los socialistas, comunistas y la gran mayoría del radicalismo (Rapoport, 1995:9).
} 
poblacional inmigratorio argentino; por otro lado, la propensión al asociacionismo de esa colonia la cual venía produciéndose desde la segunda mitad del siglo XIX y que dio lugar a la creación de clubes, centros regionales y casas de Socorros Mutuos, colaborando a estructurar aquel movimiento solidario. Unido a este factor, el asociacionismo obrero que dio lugar a la creación de diferentes sindicatos y gremios aglutinados a través de la Confederación General del Trabajo (CGT), ayudando a organizar y captar fondos para el auxilio pro-republicano. Destacamos nuevamente la influencia el exilio antifascista dentro de estas asociaciones gremiales y sindicales que, desde las décadas anteriores, intentaba introducir la cultura antifascista en la sociedad argentina. La tradición liberal y democrática colaboró también a ese posicionamiento pro-republicano, por ejemplo destacamos la hegemonía del Partido Radical antes del periodo del fraude electoral y la propia tradición republicana española. Cada uno de estos factores modelaron una sociedad argentina haciéndola muy receptiva al conflicto español y posicionándola a favor del Gobierno legal de la República (Bocanegra, 2008/2:46-47).

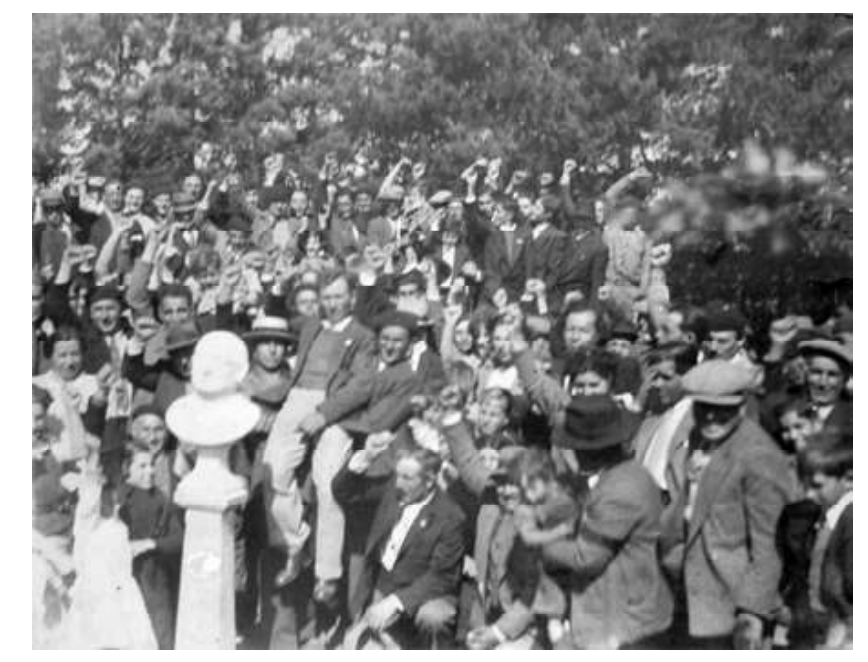

Miembros del Centro Republicano Español de Mar del Plata, Provincia de Buenos aires, 1936 aprox. Fuente: Archivo del Centro Republicano de Mar del Plata, sin catalogar.

Referente al socorro internacional a la causa republicana, estudios al respecto destacan a Argentina como el segundo país que mayormente colaboró con las ayudas humanitarias después de México (Currea-Lugo, 2004:12-13). Otros van más allá afirmando que se trató del País que más ayudas aportó considerándose el monto del dinero recaudado con los habitantes de la Nación; las evidencias 


\section{Lidia Bocanegra Barbecho}

que lo demuestran van desde los niveles de participación en los actos públicos (manifestaciones en el Luna Park, por ejemplo), las listas y las características de las donaciones (participaron desde gente muy humilde a personas adineradas), la presión que el sentimiento pro-republicano impuso a la política oficial del gobierno hacia el conflicto español, así como los testimonios de la época son factores que explicarían la magnitud de esas ayudas (Quijada, 1991:17). Ya sea la dimensión del movimiento de solidaridad, así como los debates que en torno a él se originaron a través de los partidos políticos y en la prensa contemporánea, están directamente relacionados con el fuerte impacto que supuso el conflicto español en toda la sociedad Argentina. Estudios más o menos recientes han señalado que la influencia de la Guerra Civil española no fue una cuestión coyuntural limitada a los años del conflicto en sí, sino que tuvo una influencia perdurable de largo alcance dando lugar a comportamientos políticos en el ámbito social argentino. Los actos callejeros, las colectas, las festividades (bailes, representaciones teatrales), las reuniones campestres (picnics, asados) organizados para recaudar fondos fueron a su vez espacios en los que los debates de la política interna se mezclaban con los del conflicto español. Se trató de espacios públicos en donde se reunían las bases del pueblo aglutinados por el movimiento de solidaridad, gestándose una identidad política e ideológica compartida. De hecho, las clases medias que se manifestaron en los albores del peronismo, demócratas, liberales e izquierdistas, quienes se habían movilizado durante los años de la guerra española, habían cimentado su identidad política a través y, en parte, a su experiencia en los comités de ayuda a la República española (Montenegro, 2002:8, 70, 246).

El auxilio pro-republicano revistió diversas formas de expresión: aporte material en dinero o en especies; envío de voluntarios, españoles naturalizados o hispano-argentinos incorporados en las Brigadas Internacionales o en el ejército republicano; y por último, apoyo propagandístico orientado a estimular las corrientes de opinión a favor de la causa republicana y así incrementar las ayudas mediante nuevos adeptos a la causa. La prensa jugó un rol fundamental ya que no solamente incitaba a la cooperación mediante la vía propagandística de los comités de ayuda, sino que a través de la misma la persona o entidad colaboradora podía informarse acerca de cómo estaban siendo gestionadas esas ayudas generando mayor confianza en el auxilio, lo que favorecía la continuación de esos ingresos que fueron in crescendo. Un ejemplo lo tenemos en el propio semanario del Centro Republicano Español de Buenos Aires, España Republicana, cuya función básica para el año 1939 fue la de mantener informado a todos los adherentes de la causa acerca de cómo estaban siendo gestionadas esas ayudas; procurar información acerca de cómo se iba organizando la evacuación de los 


\section{A Guerra Civil Espanhola e a América Latina}

refugiados españoles ubicados en Francia; y por último, la de continuar recogiendo dinero (inscripciones de socios...) para hacer frente a dichas ayudas humanitarias. Este método de publicitar el manejo del capital disponible se observa como una tónica común en los centros y organizaciones argentinas afines a la causa republicana.

Durante los primeros meses de la guerra el dinero en efectivo se envió mediante valija diplomática, así como los traspasos o talones a nombres de bancos ubicados en Valencia. A partir de mediados de 1937 los envíos de ese carácter se hicieron al Banco Exterior de España con sede en París, en donde el gobierno de la República había abierto una cuenta especial para canalizar las donaciones provenientes del extranjero. Referente a los envíos en especie, inicialmente también se hicieron directamente en España pero las dificultades de acceso a los puertos hicieron que se desviaran a Marsella a través de la casa consignataria Ginesta y Cía, seleccionada por indicación del Gobierno de la República desde donde eran remitidos a territorio republicano (Quijada, 1991:137).

La ayuda humanitaria argentina, activa ya desde el inicio de la guerra, fue canalizándose rápidamente a través de la creación de centenares de organismos de base a lo largo de toda la geografía nacional bajo nombres diversos tales como: Comités de Ayuda al Pueblo Español, Comités Populares de Amigos de España, Juntas Pro Socorro y Reconstrucción de España, Comités de Ayuda a España Leal, etc. Eran organizaciones muy sencillas ubicadas la mayoría de las veces en locales, habitaciones o casas cedidas, en donde empezaban a circular listas de subscripciones y en donde firmaban los diferentes donantes. Éstos donantes contribuían con dinero, paquetes de ropa y víveres, sacos de grano y harina, medicamentos, mantas, jabón, etc. La junta directiva de estos comités sufrieron las mismas divergencias políticas entre anarquistas, comunistas y la derecha liberal que en el seno del Gobierno Republicano; sin embargo, todos ellos compartían un objetivo común: centralizar la ayuda humanitaria con el fin de hacerla más efectiva a tenor de los sucesos acaecidos en España. De esta manera, hacia 1937 estos comités de ayuda se fueron decantando hacia una consolidación de dos grupos mayoritarios bajo control anarquista y comunista (Bocanegra, 2012:278-279); y un tercer grupo de republicanos moderados directamente vinculados a la Embajada. Así, en 1939 se afianzan los siguientes tres grupos hegemónicos: Federación de Organismos de Ayuda a los República Española (FOARE), creada en septiembre de 1937 bajo control del Partido Comunista Argentino (PCA); la Comisión Coordinadora de Ayuda a España en la Argentina, conocida como la "Coordinadora", fundada en marzo de 1938 por el sector anarquista y sindicalista; y la Agrupación de Amigos de la República Española (ARE), fundada en agosto de 1936 por el Centro Republicano Español de Buenos 


\section{Lidia Bocanegra Barbecho}

Aires. Todas ellas contaban con centenares de filiales y comités ubicados por todo el País. El éxito de las donaciones y participación ciudadana con estos grupos radicó no tanto en la ideología política de los mismos, sino simplemente en principios humanitarios: en aquel contexto había una neta línea divisoria entre aquellos quienes dirigían los comités de ayuda, muy politizados, y aquellos quienes conformaban la base de esa solidaridad: la población.

Hacia el final Guerra Civil española, aquellas ayudas destinadas a socorrer la población civil y ejército republicano cambiaron de dirección centrándose en auxiliar lo que quedaba del ejército republicano pero, especialmente, a los exiliados republicanos. Así pues, durante ese período y justo después de la finalización del conflicto, en abril de 1939, la ayuda humanitaria pro-argentina se sostuvo a partir de dos principios básicos: el conocimiento de las carencias tanto económicas como materiales de los exiliados españoles ubicados en los diferente campos de concentración en Francia y colonias en el Norte de África; así como el conocimiento de la represión franquista con respecto a los vencidos, no siendo factible una repatriación de los exiliados a España y sí un traslado de los mismos en tierras americanas (Bocanegra, 2008:2). La población argentina consumía estas informaciones sobre todo a través de la prensa nacional y local, quienes voceaban sin descanso el éxodo y la situación de los refugiados españoles haciendo efectivas esas ayudas y colaborando a generar una cultura de la movilización en clave de compromiso político. Por ejemplo, un artículo titulado "Condiciones en que se vive en los campos de concentración en Francia. Revelaciones de un refugiado", trata del testimonio de un refugiado ubicado en el campo de Gurs en una carta enviada a Buenos Aires:

"En este campo existen un gran número de nuestros gloriosos mutilados $e$ inválidos de guerra, cuyo estado requiere siempre un cuidado más especial por estar todavía sus heridas en cura; pero la falta de vendas, gasas, algodón, etc., empeora su situación. Enfermos del pulmón, de venéreo, etc., enfermedades que precisan un asilamiento del personal no afectado y un tratamiento adecuado, se hallan completamente abandonados, durmiendo y comiendo juntos, siendo a la vez un foco de infección y viendo como su organismo es minado por la enfermedad sin que nada puedan hacer ellos para evitar el desenlace" 4

\subsection{Confederación General del Trabajo (CGT)}

Desde el inicio de la guerra civil la causa de la República española fue símbolo de la causa obrera. Los obreros argentinos estaban repartidos en dos centrales

4. "Condiciones en que se vive en los campos de concentración en Francia. Revelaciones de un refugiado", España Republicana, Buenos Aires, 08 de julio, 1939, 8. 


\section{A Guerra Civil Espanhola e a América Latina}

sindicales: Confederación General del Trabajo (CGT) Independencia y CGT Catamarca. Tanto la una como la otra apoyarían a la España republicana. La CGT Independencia estaba dominada por socialistas y comunistas; mientras que la CGT Catamarca era de tendencia sindicalista y anarquista. Con el fin de agilizar las ayudas, ambas confederaciones de la CGT enviarían periódicamente circulares a todos los sindicatos que la integraban. Una de esas circulares, fechada en enero de 1939, formulaba una serie de indicaciones a sus afiliados destacándose la de realizar "una intensa propaganda entre sus asociados con objeto de que los mismos circunscriban sus actividades de ayuda a España en torno de las Comisiones Auxiliares Internas", añadiendo: "que debe tenerse como obligación moral ineludible para los trabajadores agrupados en la Confederación General del Trabajo la suscripción al medio jornal solicitado" ". En agosto de 1939, ante la grave situación en la que se encontraban los trabajadores españoles refugiados en Francia, la CGT giró a la Federación Sindical Internacional de París la suma de 35.000 pesos argentinos ${ }^{6}$.

Los conflictos locales entre las distintas agrupaciones obreras, así como el influjo de los enfrentamientos de la España republicana entre elementos vinculados a la Unión Soviética y otras formaciones de izquierda, acentuaron la brecha abierta dentro del sector pro-republicano cuyas prácticas, manifiestas a través del movimiento de solidaridad, se fueron agrupando tras la dirección del sector comunista y anarquista. Así pues, en marzo de 1938 el sector anarquista funda la Comisión Coordinadora de Ayuda a España en la Argentina, actuando con independencia de la FOARE, de orientación comunista.

\subsection{Federación de Organismos de Ayuda a los República Española (FOARE)}

En 1939, la FOARE cambió de nombre en respuesta a la adaptación de las ayudas humanitarias al nuevo decreto, de fecha de 30 de mayo de 1939, promulgado por el presidente Roberto M. Ortiz. Este Decreto estipulaba la prohibición de las asociaciones extranjeras, con el objetivo de que no se radicalizara en el país ningún foco social-comunista entre una población mayoritariamente inmigrante europea. A partir de entonces pasó a denominarse: Federación de Organismos de Ayuda a los Republicanos Españoles (igualmente FOARE).

5. "La Confederación General del Trabajo y la Ayuda a España Leal", El Trabajo, Mar del Plata, 20 de enero, 1939, 3.

6. "Con destino a los refugiados españoles giró una importante suma la Confederación General del Trabajo”, El Trabajo, Mar del Plata, 9 de agosto, 1939. 


\section{Lidia Bocanegra Barbecho}

Este organismo, junto con el SERE (Servicio de Emigración de los Republicanos Españoles) y lo cuáqueros ingleses, fueron quienes financiaron y seleccionaron mano de obra cualificada e intelectuales de entre los millares de refugiados ubicados en Francia con destino a Chile. A mediados de 1939, la FOARE inició una campaña bajo el lema "Españoles a Chile!" en donde se acordó abonar 25 pesos por cada refugiado admitido en las listas elaboradas por Pablo Neruda y el SERE y que cada pariente argentino debía pagar por el mismo ${ }^{7}$. Dentro de esta campaña tuvo un papel fundamental la Comisión Argentina de Socorro a las Víctimas de España (CASVE) bonaerense, adherida a la FOARE. Tomando la consigna de enviar: "i1000 refugiados a Chile durante el mes de Abril!", con un cálculo aproximado de 100.000 pesos para poder fletar un barco, la FOARE inició una importante acción mediática para llevar a cabo dicho objetivo no solamente a través del órgano de prensa afín: La Nueva España, sino también a través de la prensa local como por ejemplo el periódico socialista, El Trabajo, de Mar del Plata. Tal importancia recobró esta idea que la federación abrió en su misma sede una Oficina de Informe sobre los Refugiados en combinación con el Comité Internacional de Coordinación y de Información para la Ayuda a la España Republicana (CICIAER) ${ }^{8}$, organismo este último creado por el gobierno de la República el 13 de agosto de 1936 con sede en París y destinado a la coordinación de los esfuerzos a favor de la España republicana a escala internacional. Colaboraba con la FOARE el Comité Argentino de Mujeres pro Huérfanos Españoles, quien le entregó en el mes de marzo de 1939 la cantidad de 3.000 pesos argentinos. Este Comité fue una de las organizaciones que más colaboró en auxiliar a los refugiados infantiles destinados a Chile, asistiendo a la creación de una colonia en dicho País para los 130 niños españoles que viajarían a bordo del Winnipeg ${ }^{9}$. Asimismo, durante los meses de noviembre y diciembre este Comité agilizó una campaña de ayuda a los todavía 20.000 niños republicanos que se encontraban ubicados en los campos de concentración de Saint Cyprien y Argelés donde, decía: "deben dormir sobre la arena húmeda, con una alimentación harto precaria, sin ropas de abrigo, ni colchones. La asistencia médica no existe. Falta la leche, el pan, los alimentos más indispensables"10.

7. "Mil españoles refugiados en Francia serán trasladados a Chile", El Trabajo, Mar del Plata, 8 de junio, 1939.

8. "Una campaña a favor de los españoles refugiados en Francia", El Trabajo, Mar del Plata, 10 de abril, 1939.

9. "El Comité Argentino de Mujeres Pro Huérfanos españoles sostendrá una colonia de niños en Chile", El Trabajo, Mar del Plata, 24 de junio, 1939.

10. "Piden ayuda urgente para 20.000 niños españoles refugiados en Francia", El Trabajo, Mar del Plata, 22 de diciembre, 1939. 


\section{A Guerra Civil Espanhola e a América Latina}

A medida que el gobierno de la República iba sufriendo derrota tras derrota, algunas organizaciones de ayuda humanitaria argentinas se fueron disolviendo, tal es el caso de la Junta Argentina de Médicos pro Ayuda Sanitaria a España Republicana (JAMASER), creada en 1937 y adherida a la FOARE. Según la junta ejecutiva de este organismo, los motivos de la disolución se debían al considerar que todos los esfuerzos a la España Republicana debían orientarse a socorrer a los refugiados, ya que la existencia de la JAMASER podría gravitar la economía recaudatoria a la par de crear dificultades a la acción común de los demás organismos de auxilio. El saldo de la ayuda humanitaria con el que contaba la Junta en el momento de disolver la organización fue el envío a la España republicana de 38 ambulancias, 2 hospitales móviles, numeroso instrumental quirúrgico y medicinas, todo ello valorado en unos $226.629,45$ pesos $^{11}$. Todos los aportes materiales de la JAMASER eran enviados a través de la Central Sanitaria Internacional, con sede en París, la cual se encargaba de centralizar toda la ayuda sanitaria a España trabajando en estrecha colaboración con la Jefatura de Sanidad del Ejército Republicano.

Como tantas otras organizaciones, la JAMASER contaba con una Comisión Femenina integrada por Dalila de Vergara, entre otras, quien encabezó una campaña de ayuda a los niños españoles en el mes de diciembre de 1938, siendo continuada durante los primeros meses de $1939^{12}$.

\subsection{Comisión Coordinadora de Ayuda a España en la Argentina (Coordinadora)}

Colaboraron estrechamente con la Coordinadora la filial argentina de la Solidaridad Internacional Antifascista (SIA), fundada en España en mayo de 1937 por la CNT-FAI y las Juventudes Libertarias; la Federación AnarcoComunista Argentina (FACA) y su Comité Sindical de Ayuda al Proletariado Español; así como la Federación Obrera de la República Argentina (FORA). Todas ellas estaban vinculadas con la organización sindical anarquista española: CNT-FAI.

Hacia el final de la guerra civil, la Coordinadora donó una importante cantidad de dinero en efectivo para que éste fuera destinado a los campos de concentración franceses; por ejemplo, en el mes de mayo de 1939 giró la cantidad de 200.000 francos franceses ${ }^{13}$. Asimismo, durante ese período la filial argentina de la SIA creó en Buenos Aires la Comisión de Ayuda a los Exiliados Antifascistas. A finales

11. "Se disolvió un organismo creado para ayudar a los Republicanos españoles", El Trabajo, Mar del Plata, 23 de junio, 1939.

12. "Por los niños españoles", España Republicana, Buenos Aires, 7 de enero, 1939, 6.

13. "La ayuda argentina a los refugiados españoles", El Trabajo, Mar del Plata, 12 de mayo, 1939. 


\section{Lidia Bocanegra Barbecho}

del mes de junio de 1939, esta Comisión inauguraría un servicio de envío de paquetes estándar de varios tipos, semejantes a los que ya estaba organizando la FOARE, los cuales eran enviados semanalmente a París vía aérea. Allí la filial francesa hacía la respectiva distribución a los destinatarios de los campos y refugios, haciéndose cargo de los posibles extravíos. Los paquetes eran de cuatro tipos: "Paquete $\mathrm{A}$, conteniendo lo preciso para la higiene, tabaco, etc., al precio de tres pesos cincuenta centavos; Paquete A-B, con el contenido del A, mas ropa, al precio de siete pesos; Paquete combinado A-B-C, más todo lo necesario para las mujeres y los niños, al precio de pesos siete" 14 .

Otra de las organizaciones que actuaba en colaboración con la Coordinadora fue la Comisión Argentina pro Niño Español (CANE). En febrero de 1939 esta Comisión inició las gestiones para facilitar el traslado de 200 niños españoles en Argentina. La idea era ubicarlos primeramente en Francia, instalándolos en colonias-escuelas, para su posterior traslado en territorio argentino. La iniciativa de auxiliar y asilar a los niños españoles partió del senador socialista Alfredo L. Palacios con quien colaboró el diputado radical, José Peco. Ambos acordaron un "plan tendiente a prestar efectivo amparo [...] a los niños que en España han quedado sin padres ni hogar" 15 . Pronto se sumaron a esta causa, entrando a formar parte del comité de la CANE, personalidades destacadas como el Premio Nobel de la Paz en 1936, el doctor Carlos Saavedra Lamas; Ramón J. Cárcano, embajador argentino en Francia, etc. Esta Comisión elevó una nota firmada por estas personalidades al presidente Ortiz, en donde se solicitaba asilo a los huérfanos españoles para ser entregados a familias argentinas que reclamaran su adopción. Pedía, asimismo, el permiso de entrada a los refugiados españoles comprendidos en las siguientes categorías: primero los niños desamparados; segundo los ciudadanos españoles con familia en la Argentina; tercero los trabajadores del campo; y cuarto los intelectuales, hombres de ciencia y artistas. En dicha nota la CANE manifestaba el compromiso en otorgar "tierras y elementos de labranza y granja a los niños españoles que pudieran ser traídos"; la formación de las granjas-escuelas y la obligatoriedad de asistencia a las mismas correría a cargo de la propia Comisión y de las organizaciones afines ${ }^{16}$. Sin embargo, a pesar de todas estas facilidades, el gobierno no secundó la iniciativa amparándose en un discurso proteccionista con respecto a los refugiados a quienes consideraba "elementos indeseables", como veremos más adelante.

14. "Víveres y ropas para los exiliados en Francia", El Trabajo, Mar del Plata, 27 de junio, 1939.

15. "Gestionará el Senador Palacios medidas a favor de los huérfanos españoles", El Trabajo, Mar del Plata, 16 de febrero, 1939.

16. "Se solicita al Ministro Taboada autorización para traer al País un contingente de niños españoles", España Republicana, Buenos Aires, 25 de marzo, 1939. 


\section{A Guerra Civil Espanhola e a América Latina}

A pesar de todo, y con posterioridad a la guerra civil, la CANE conseguiría fundar en la ciudad francesa de Lyon un Hogar Argentino del Niño Español Refugiado que, a partir de mayo de 1939, atendió a centenares de niños evacuados de la zona ocupada y que se mantendría durante algunos años bajo la dirección de Facundo Roca (Quijada, 1991:149).

\subsection{Agrupación de Amigos de la República Española (ARE)}

El Centro Republicano Español de Buenos Aires (CRE) fue una de las más viejas entidades de raigambre republicana. Gracias a su red de filiales por todo el País pudo llevar a cabo una fuerte campaña solidaria con respecto a la República española. El 25 de agosto de 1936, por iniciativa del Centro se creó la Agrupación de Amigos de la República Española (ARE), cuyo propósito fundamental era la de encauzar la voluntad de apoyo la República entre los españoles de Argentina. Igualmente, pretendía ser reconocida como la única organización de apoyo a los refugiados. Esta pretensión de exclusividad solidaria respondía a una política de actuación adoptada por el Centro en donde se intentaba prescindir de la política fomen-tando, por otro lado, las operaciones de socorro. De esta manera, tanto la FOARE como la Coordinadora, comunista y anarquista respectivamente, eran vistos por el Centro como organismos con una fuerte coloración política local que comprometía la prescindencia ideológica que debían respetar según las leyes argentinas, pues a su juicio colocaban la campaña solidaria en un espacio conflictivo a la vez que la inhibían (Schwarzstein, 2001:107). De esta manera, el CRE se convirtió en el núcleo del sector gubernista moderado, con el apoyo velado de la embajada, muy celoso de no ingerirse en política local y cauto en los extremismos ideológicos. Así pues, en respuesta al decreto promulgado por el Presidente Ortiz acerca de la prohibición de las asociaciones extranjeras, en agosto de 1939 y con el objetivo de evitar que la obra solidaria de la Agrupación pudiera ser considerada como una actividad política, la ARE cambió de nombre pasándose a llamar a partir de entonces: Fraternidad Española ${ }^{17}$.

Justo antes que finalizara el conflicto español, la ayuda se orientó en socorrer a los exiliados ubicados en los campos de concentración franceses con el objetivo de paliar las necesidades básicas de los mismos, así como en el intento de evacuar a esos refugiados hacia tierras americanas: concretamente hacia México, Chile y República Dominicana. Así pues, el Centro Republicano Español a través de la ARE giró semanalmente la cantidad de 10.000 pesos argentinos a su representante del Comité de Ayuda al Refugiado en Marsella ${ }^{18}$ :

17. "Fraternidad Española", España Republicana, Buenos Aires, 19 de agosto, 1939, 10.

18. "Por los refugiados en Francia", España Republicana, Mar del Plata, 4 de marzo, 1939. 
Lidia Bocanegra Barbecho

"Se realizó el primer giro el día 17 de febrero y por él se pusieron a la orden de nuestros delegados 86.655.11 francos. El segundo giro se realizó el día 24 de febrero y por él llegaron a Marsella 86.730.- francos y el día 3 de marzo se efectuó el tercer giro, equivalente a 86.580.- francos (...)"19.

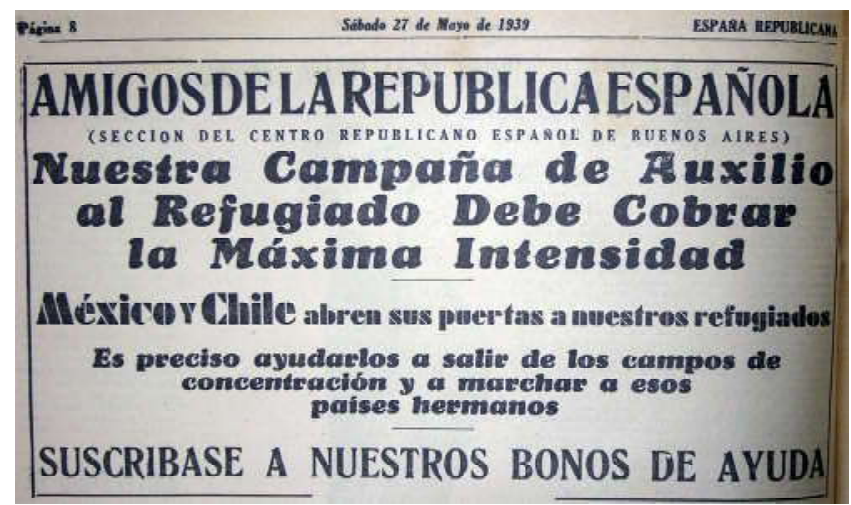

Propaganda publicada por el semanario del Centro Republicano Español de Buenos Aires a favor de los exiliados republicanos.

Fuente: España Republicana, Buenos Aires, 27 de mayo de 1939, 8.

Durante los meses de septiembre y octubre de 1939, Fraternidad Española había remitido al SERE ciento ochenta y un expedientes de evacuación de refugiados a América, resolviéndose de todos estos ciento cincuenta y uno. El SERE había conseguido subvencionar el pasaje a cuarenta y seis de esos ciento cincuenta y un expedientes ${ }^{20}$.

Dentro del Centro Republicano Español, a modo de filial del mismo se creó la Agrupación Juvenil Republicana (JAR) con sede en la misma secretaría del Centro. Se trató de una asociación cuyos adherentes eran jóvenes republicanos los cuales organizaron actos culturales y artísticos, cuyos fondos eran remitidos a la ARE con destino a la España republicana ${ }^{21}$. A parte de las filiales que tuvo el Centro Republicano Español en casi todo el País, también contaba con el apoyo de los centros regionales bonaerenses tales como el Casal Català. En 1939 su presidente, Jaime Llauró, estableció lazos solidarios con el Centro Republicano y con el presidente de éste, Miguel Servera, para formalizar las ayudas destinadas a los exiliados.

19. "La ayuda a los españoles refugiados en Francia", España Republicana, Buenos Aires, 11 de marzo, 1939, 6.

20. "Fraternidad Española. Porqué nos esforzamos en mantener la ayuda a los refugiados", España Republicana, Buenos Aires, 4 de noviembre, 1939, 10.

21. "J.A.R. Agrupación juvenil republicana”, España Republicana, Buenos Aires, 25 de marzo, 1939. 


\section{A Guerra Civil Espanhola e a América Latina}

\section{El gobierno argentino se protege: la política inmigratoria restrictiva}

Desde el inicio mismo de la Primera Guerra Mundial y en las décadas sucesivas, los distintos gobiernos democráticos, militares y conservadores argentinos a través de la vía administrativa fueron cerrando sus fronteras a una migración transoceánica que, cada vez más, encuadraba al inmigrante dentro de una amenaza social revolucionaria. Ésta nueva inmigración se iba despegando de aquella vieja figura del inmigrante económico agricultor, para ir dejando paso a uno nuevo: politizado y más vinculado al sector servicios e industrial. El hermetismo fronterizo tuvo una relación directamente proporcional a la crisis económica del momento, de tal manera que en etapas de relativa calma económica esas vías administrativas se iban relajando permitiéndose la entrada al País a los inmigrantes en función de la arbitrariedad de los funcionarios. Por el contrario, en época de crisis económica y social (auge del marxismo, crack de 1929...), se decretaban una serie de medidas restrictivas con el fin de obstaculizar la entrada de inmigrantes, tales como: obtener certificados policiales o judiciales, ampliar las categorías excluibles por razones médicas o sociales, poseer un contrato de trabajo, etc. Asimismo, se daba instrucciones al personal consular, con amenazas veladas inclusive, para que acentuasen la rigidez de los controles en la gestión de expedientes y disuadieran toda migración que se dirigiese a las ciudades (Devoto, 2001:282-283).

Hacia mediados de la década de 1930 empezó a acentuarse la figura del refugiado como consecuencia de los conflictos desencadenados en Europa. Por otro lado, los conflictos ideológicos entre fascistas y antifascistas en el plano internacional se hicieron cada vez más influyentes en el debate político argentino, causando en la cúpula dirigente conservadora un temor hacia la amenaza que supondría la entrada al País de elementos subversivos: los refugiados políticos. A este recelo se añadió el problema de controlar las enormes fronteras terrestres, lo que había causado la entrada al País de inmigrantes ilegales provenientes de países limítrofes. Consecuencia de todo esto fue el incentivar todavía más el hermetismo fronterizo mediante decretos, argumentados con discursos proteccionistas. El Gobierno afirmaba que el refugiado "no podía ser considerado un inmigrante ya que la venida era una decisión forzada de la persona y no voluntaria (...) ello limitaba su capacidad productiva y su voluntad de integración en el nuevo país" (Devoto, 2001:287-288). Asimismo, basándose en el hecho de que los refugiados provenían en su mayoría del ámbito urbano, con profesiones del sector terciario, iba en contra de las premisas básicas que la Ley de Inmigración y Colonización de 1876 demandaba al inmigrante: ser agricultor y proveniente de las áreas rurales. Sin embargo, paralelo a este discurso oficial había otro 
oficialista en donde las restricciones en materia migratoria tenían su origen no ya en las causas económicas, sino primordialmente en razones políticas: "el temor a recibir refugiados cuyos gobiernos los acusaban de izquierdistas y enemigos del orden establecido" (Spitta, 1989:22).

Es en este escenario cuando el gobierno del Presidente A. P. Justo promulgó un decreto en 1936 con el objetivo de prohibir "la entrada al país a toda persona que constituyera un peligro para la salud física y moral de la población, o conspirara contra la estabilidad de las instituciones creadas por la Constitución nacional" (Schwarzstein 2001a:47). Este decreto disponía nuevos mecanismos de control y fiscalización: se ampliaba la vigilancia en todos los medios de transporte, incluido el avión, y a todas las clases de pasajes dándose plenas competencias al Ministerio del Interior, a la policía y en especial a la División del orden social (policía política), para ejercer ese control. Asimismo, se exigía la realización de fichas del inmigrante que incluyera no solamente una fotografía, sino también un registro dactiloscópico. Dos años más tarde, bajo la presidencia de R. M. Ortiz, en julio de 1938 se promulga un nuevo decreto caracterizado no tanto por su naturaleza restrictiva, sino por representar el mayor esfuerzo del Gobierno argentino por reducir al mínimo la inmigración a través de mecanismos administrativos, según estudios al respecto. La característica principal de este nuevo decreto fue la inclusión de un Permiso de Desembarco, además de la aportación de toda una serie de documentación legalmente requerida: pasaporte; certificado médico; informe del Consulado en el que constara las motivaciones del viaje, nacionalidad, ocupación tiempo de permanencia, medios de vida del interesado, etc. El Permiso de Desembarco debía ser solicitado desde Europa a través de los consulados argentinos, el cual era concedido por la Dirección de Migraciones de Buenos Aires previo asesoramiento de un Comité Consultivo formado, éste último, por funcionarios de los ministerios del Interior, Relaciones Exteriores y Culto y Agricultura. Dicho de otro modo: este nuevo decreto dejaba a total discreción al Comité Consultivo quien podía ingresar y quien no (Devoto, 2001:288-289).

Quienes entraban en calidad de Turista no tenían que presentar el Permiso de Desembarco y todo el expediente asociado al mismo, solamente debían solicitar en los consulados argentinos un Certificado de Turismo. Cuando ingresaban tenían que depositar la documentación personal en la Dirección de Inmigraciones, la cual era devuelta en un plazo no mayor de tres meses: período máximo de permanencia como turista. A partir de entonces, una significativa presencia de españoles y judíos habían empezado a ingresar en condición de turistas como consecuencia de la guerra misma y persecuciones varias. 


\section{A Guerra Civil Espanhola e a América Latina}

Paralelo al discurso proteccionista, había otro de connotaciones racistas cuyos matices se dejaban ver en las interpelaciones parlamentarias. El gobierno conservador de A.P. Justo utilizaba un lenguaje racista para referirse al nuevo extranjero: el refugiado por causas políticas y raciales; decía: "estamos en verdad, privados de los elementos más útiles y más cercanos y amenazados de ser el receptáculo de lo que "expele" Europa" (Schwarzstein, 2001b:253). Mismo lenguaje utilizaría los ministros de Relaciones Exteriores y Culto y Agricultura: José María Cantilo y José Padilla, respectivamente, quienes fueron los que más trabajaron en intentar rechazar por todos los medios ese tipo de inmigración; argumentaban:

"La inmigración trabajadora es la que ha hecho la grandeza del país, no es el político ni el refugiado, ni el perseguido ni el expulsado, sino el inmigrante italiano, el inmigrante español, el vasco francés y el vasco español, que venían en otra época y no llegan ahora (...) tendrían una limitada capacidad productiva así como una escasa voluntad de integración" (Schwarzstein 2001a:49).

Con este escenario proteccionista y muy impermeable, el Gobierno argentino no otorgó el estatus de inmigrantes a esos refugiados argumentando que: "el indeseable, el expulsado, el refugiado político, el refugiado racial que huye de Alemania, Austria, de Italia, de España, no es un inmigrante" (Schwarzstein 2001b:253). Así pues, al republicano español se le tildó de "indeseable" con respecto a los "deseables" caracterizados, éstos últimos, por los inmigrantes económicos de finales del siglo XIX e inicios del siglo XX. No sería hasta 1948 cuando Argentina reconocería el estatus de refugiado a los republicanos españoles y judíos; con anterioridad a esa fecha, exceptuando casos muy particulares, los refugiados españoles no recibieron asilo político por parte del Gobierno argentino. Estos refugiados ingresaron en el País mediante Pasaportes Nansen o bien con pasaportes emitidos por el Gobierno Republicano. El primero se trataba de un Certificado internacional de identificación para personas desplazadas y era emitido por la High Comission for Refugees, organización creada por la Liga de las Naciones en 1921. Referente a los pasaportes emitidos por el Gobierno de la República, no eran aceptados por Argentina ya que se trataba de un gobierno no reconocido por las autoridades nacionales. Una de las exigencias del gobierno argentino para admitir a los españoles era que sus pasaportes fueran visados por el gobierno franquista, a sabiendas de que eso era prácticamente imposible ya que éste negaba la visa a los así despectivamente llamados "rojos".

La opinión democrática y liberal argentina representados por la oposición política (socialistas y radicales), así como intelectuales pro-republicanos, ayudados por la prensa afín unificaron sus esfuerzos para atacar al Gobierno en relación a las políticas migratorias. Ya en 1938 las izquierdas democráticas argentinas se 


\section{Lidia Bocanegra Barbecho}

movilizaron enfrentándose contra el Poder Ejecutivo para que reabriera las fronteras. El 28 de noviembre de ese mismo año, en el Luna Park se celebró una asamblea ofrecida por la Liga Argentina por los Derechos del Hombre votándose la siguiente resolución: "Bregar por la derogación de las medidas restrictivas de la inmigración y del derecho de asilo, de manera que el país cobije a todos los perseguidos que deseen colocarse al amparo de sus instituciones" 22 . Durante el año 1939 hubo una serie de interpelaciones parlamentarias por diputados del Partido Socialista Argentino y Unión Cívica Radical con respecto a las restricciones migratorias. Por ejemplo, Juan A. Solari, del bloque socialista, presentó ante la Cámara de los Diputados un proyecto de Ley en donde se quería incorporar a los refugiados como inmigrantes "deseables", autorizándose la entrada al País a toda "persona extranjera que desee trabajar la tierra o ejercer en nuestro país una industria, oficio, profesión, comercio o arte, útiles y lícitos". El proyecto de Ley excluía no tan solo a los enfermos sino también a "aristas teatrales, profesores, conferencistas, obreros, y empleados adiestrados o especializados en algún arte o industria nueva no establecida o desarrollada suficientemente en el país"23. Si bien el Partido Socialista intentaba suavizar el Proyecto de Ley, adaptándolo lo máximo posible a aquel hermetismo migratorio, nunca fue considerado por el Gobierno. Éste se justificó argumentando que si bien los decretos de julio de 1938 parecían contrariar la Ley de Inmigración de 1866, estos se debían a un deseo de defender los trabajadores argentinos de toda competencia y de atraer a una población especialmente seleccionada para los trabajos del campo. Igualmente, argumentaba que "el indeseable, el refugiado político, el refugiado racial, que huye de Alemania, de Austria, de Italia, de España no era un inmigrante" 24 , y que las medidas restrictivas res-pondían a una política de emergencia de limitaciones inmigratorias como una defensa con la infiltración nazista.

Este mismo diputado, Solari, presentó también un proyecto para radicar en Argentina a un millar de familias españolas que se encontraban en los campos de concentración franceses. A pesar de que estas familias contarían con apoyo económico del Gobierno de la República en el exilio (gastos de viaje y manutención de los primeros días del arribo) no fue aceptado por la Cámara de los Diputados, esgrimiendo los mismos argumentos proteccionistas de siempre. Interpelación tras interpelación constantemente caían en saco roto. La prensa liberal e izquierdista vocearon sin descanso todas estas interpelaciones cuestionando la

22. "Se propicia una acción pública para que se abran las puertas del País a los perseguidos por el fascismo", El Trabajo, Mar del Plata, 21 de enero, 1939.

23. "Un amplio proyecto de Ley de Inmigración ha sido presentado a la Cámara de los Diputados", El Trabajo, Mar del Plata, 15 de agosto, 1939

24. "Régimen de emergencia en materia inmigratoria", El Trabajo, Mar del Plata, 22 de agosto, 1939. 


\section{A Guerra Civil Espanhola e a América Latina}

política inmigratoria argentina; sin embargo, aquella más conservadora omitía hablar de este aspecto, o bien trataba la misma afilando la pluma para atacar al refugiado político y racial en todos los sentidos. Uno de estos periódicos argumentaba:

Defendamos nuestro patrimonio, salvemos al país del peligro que significa el arribo de esa clase de extranjeros, dañinos, criminales, amorales; delincuentes en una palabra. Contra ellos, todas las precauciones serán siempre pocas; para ellos, coloquemos cuanto obstáculo sea posible. Prevengamos, de ahora en más. Que ya tenemos que curar demasiado, con la enorme cantidad de extranjeros indeseables, perturbador del orden; disolvente, enemigo de la nacionalidad, del hogar y de los bienes ajenos, que se ha infiltrado en el país ${ }^{25}$.

\section{Conclusiones}

A diferencia de otros países latinoamericanos, tales como México o Chile, Argentina nunca se caracterizó por ser un país que acogió a los exiliados republicanos tal y como se ha mencionado en los apartados anteriores. Socialmente fue un País muy activo en el tema del socorro a la República española y a los refugiados; pero este auxilio no consiguió que el Gobierno abriera sus puertas a los exiliados.

A pesar de todo este hermetismo inmigratorio, hubo una excepción en relación a los refugiados vascos asentados en los campos de concentración franceses. Se trató de una iniciativa llevada a cabo por la colonia vasca a través del recién creado Comité Pro Inmigración Vasca en 1939. Estuvo presidida por José Urbano Aguirre, siendo integrada por distinguidas personalidades de las más prestigiosas instituciones argentinas, tal es el caso de Diego Joaquín Ibarbia: secretario del Instituto de Colonización de la Provincia de Buenos Aires. Este Comité consiguió asentar 1400 refugiados vascos en Argentina. Estudios al respecto señalan el éxito de esta operación a toda una serie de factores tales como: la presencia de destacados miembros en el Comité con plenos contactos con la cúpula dirigente; la amplia tradición de la colonia vasca vinculada históricamente con una inmigración netamente agrícola; un significativo núcleo descendientes de esta inmigración vasca que supo consolidar rápidamente una reputada posición político-social y económica, tal es el caso del propio Presidente Roberto M. Ortiz Lizardi, hijo de un vizcaíno y una navarra; el lobby pro-vasco utilizado por el Comité Pro Inmigración Vasca que hacía referencia a la laboriosidad en el mundo rural y catolicismo de los antiguos vascos llegados al País (Schwarzstein, 2001a:69-70; Senkman, 1995: 53, 76). Este éxito se fue consolidando con la promulgación del Decreto el 20 de enero de 1940 que establecía lo siguiente:

25. "Nacionalidades", El Progreso, Mar del Plata, 21 de enero, 1939. 
Lidia Bocanegra Barbecho

\begin{abstract}
"El Ministerio de Agricultura permitirá el ingreso al país de inmigrantes vascos, residentes en España o en Francia, con la documentación que posean y bajo garantía moral y material en cada caso, del Comité Pro Inmigración Vasca, o la que en su defecto puedan suministrar los funcionarios consulares respectivos, sobre los antecedentes de buena conducta y aptitudes físicas y morales de las personas en cuyo favor interceda el citado Comité" (Anasagasti, 1988:25).
\end{abstract}

Este decreto fue ampliado el 18 de julio de 1940 con otro que comprendía a los vascos sin distinción de origen y de lugar de residencia, asimismo otorgaba privilegios al Comité Pro Inmigración Vasca para intervenir en la regularización de la situación de los pasajeros vascos que ya se encontraban en el País. Ambos decretos discriminaban al resto de refugiados españoles, denunciado en su momento por el ex Embajador en Argentina, Ángel Ossorio y Gallardo, quien solicitó hacer extensivo los mismos a todos los republicanos, decía: "Buenos son ellos, pero los demás españoles no son inferiores". No se hizo nunca. Algunos estudios catalogan el Comité como si de una agencia para-diplomática se tratase pudiendo contratar indistintamente refugiados vascos, fueran o no agricultores (Senkman, 1995:57). A parte de los 1400 exiliados vascos ingresados en Argentina, el estallido de la Segunda Guerra Mundial impidió que se realizara una emigración masiva por la peligrosidad que suponía la presencia de buques de guerra y submarinos en los mares, así como la imposibilidad conseguir barcos para emprender la travesía hacia América.

El grupo más numeroso de republicanos que llegó a la Argentina antes de 1940, justo al finalizar la guerra española, lo hizo a bordo del vapor francés Massilia. Arribó al puerto de Buenos Aires el 5 de noviembre de 1939; a bordo del mismo se encontraban ciento cuarenta y siete republicanos españoles en tránsito a diversos destinos: ciento treinta y dos a Chile, seis a Paraguay y nueve a Bolivia ${ }^{26}$. A pesar de que ninguno de ellos tenía a Argentina como lugar de destino, cincuenta consiguieron permanecer en el país. Esto se logró gracias a la actuación del director del diario Crítica, Natalio Botana, quien consiguió del presidente Ortiz el visto bueno (Schwarzstein, 1997:442).

A parte de esta excepcionalidad vasca (1400 refugiados) y del pequeño grupo de refugiados a bordo del Massilia (50 en total), la entrada al País de los exiliados republicanos queda caracterizada por ingresos individuales o pequeños grupos, quienes ayudados por connacionales afines, o bien por familiares y gente influyente, pudieron establecerse en Argentina. Por ejemplo, en un informe confidencial del Partido Comunista Español, fechada en septiembre de 1940, basándose en los datos publicados por la Central Sanitaria suiza se argumentaba

26. El semanario España Republicana editó la lista completa de pasajeros: "Un grupo de republicanos españoles llega a la Argentina”. España Republicana, Buenos Aires, 11 de noviembre 1939, 7. 


\section{A Guerra Civil Espanhola e a América Latina}

que habían emigrado al país argentino 250 refugiados desde los campos de concentración franceses, de los cuales 20 eran miembros del partido ${ }^{27}$.

Debido a esta tipología de exilio no masivo es difícil cuantificar numéricamente el mismo; escasos estudios al respecto ofrecen la cifra aproximada de 2.500 los republicanos ingresados en Argentina (Schwarzstein, 2001a:83). Igualmente, para el período de 1950-1970 se encuentran unas 400 inscripciones de refugiados españoles en las Representaciones españolas en Argentina, siendo los vascos, seguidos por los catalanes y provincias castellanas los que encabezaron el mayor porcentaje de entradas (Rubio, 1977:271-272).

Argentina siempre fue País con gran atractivo para los exiliados, ya fuera por afinidad cultural debido a la vasta presencia de inmigrantes españoles, o por tratarse de una sociedad afín con la causa republicana. Esto provocó que algunos refugiados decidieran exiliarse en este País gaucho sorteando aquellas barreas restrictivas mediante el uso de las "cartas de llamada", o bien a través de la condición de "turistas" o "en tránsito". Lo primero, puesto en práctica en 1932, se legitimó nuevamente bajo decreto en 1938. Este decreto autorizaba a la Dirección General de Inmigración a conceder los permisos a parientes de radicados en el País, sin que éstos tuviesen que tramitarlos ante los cónsules. Las enormes fronteras argentinas eran difíciles de controlar, facilitando que muchos refugiados ingresaran clandestinamente a través de las mismas. Otros, aprovechando la condición de pasajero en tránsito optaron por la fuga para permanecer ilegalmente en el País. Lo mismo sucedía con aquellos ingresados como turistas. Tanto a unos como a otros, las conexiones familiares e incluso connacionales contribuyeron a legalizar la situación de los mismos (Bocanegra, 2009:220).

A pesar de considerarse 1939 como fecha fundacional del exilio republicano, cabe destacarse que desde agosto de 1936 empezaron a llegar a Argentina los primeros barcos con exiliados españoles anónimos, a quienes pronto se les uniría el exiliado intelectual (artistas, profesores universitarios, escritores, periodistas, etc.) y familias argentinas que se encontraban en España al estallar la guerra conformadas, muchas de ellas, por antiguos emigrantes españoles: Santo Tomé, Capitán Sarmiento, San Martín, Almanzora, Campana, Mendoza, Kerguelén, Highland Monarca, Alcántara, Jamaique, Alsina (Ortuño, 2010:61-62). Referente a la periodización de llegadas de los exiliados, se establecen tres momentos diferenciados: la primera, representada durante el período de la contienda (193639) y caracterizada por la llegada de personas individuales o en pequeños grupos

27. Archivo Histórico del Partido Comunista de España, Madrid, Caja 97/2.1: Francia, Refugiados españoles, Informes y Caja 102/1.1: América Latina Generalidades, Emigración Política, Informes. 


\section{Lidia Bocanegra Barbecho}

familiares, cuyo itinerario se efectuaba principalmente desde la península siguiendo la ruta Alicante-Orán-Marsella. El segundo momento viene representado con la derrota republicana (enero-febrero 1939) hasta 1945. Caracteriza este período el exilio más masivo a Argentina hasta 1942 (caso de los vascos y Massilia); y uno más puntual (1942-45) debido a la evolución de la guerra europea que dificultaba el ingreso de los mismos. Por último, un tercer momento que comienza en 1946, cuando se firman los primeros acuerdos sobre migración entre Franco y Perón, y finaliza con la dictadura española (1972). Dentro de esta última etapa, hacia mediados de los años cincuenta cesa la emigración española en Argentina y el exilio se reduce considerablemente Alsina (Ortuño, 2010:61-63); algunos de los barcos utilizados por estos exiliados para ingresar en el País fueron el Cabo de Buena Esperanza y Cabo de Hornos.

Así pues, el período de 1941-1945 es el que registró un menor ingreso de inmigrantes y exiliados en general. Las causas que provocaron este descenso fueron varias: el estallido de la Segunda Guerra Mundial que comportó un mar repleto de buques de guerra dificultando el traslado de pasajeros; bloqueo del ingreso a los refugiados en tránsito que habían logrado permisos de entrada a los países limítrofes, debido a un escándalo por soborno y venta de visas a refugiados judíos en el consulado argentino de Marsella. Por último, una escasa actuación de la oposición, socialista y radical, y del auxilio pro-republicano civil en la absorción de refugiados españoles para el período de 1940-42; éstos se centraron en agilizar peticiones al Gobierno para que intercediera ante el Gobierno franquista con el objetivo de impedir las ejecuciones sumarias con respecto a los refugiados trasladados a España por el ejército alemán, así como el cese de ejecuciones a republicanos condenados a muerte (Senkman, 1995:70-72).

A medida que transcurrían los años, el debate sobre la Guerra Civil se fue cerrando y aquel antifascismo como elemento unificador se fue diluyendo. El protagonismo de la Segunda Guerra Mundial y los sucesivos gobiernos militares argentinos bajo golpe de Estado hicieron del problema migratorio un tema policial, siendo la preocupación central cómo reprimirlo. 


\section{Referencias}

ANASAGASTI, Iñaki. Homenaje al Comité Pro-Inmigración Vasca en Argentina (1940). San Sebastián: Txertoa, 1988.

BOCANEGRA BARBECHO, Lidia. Argentina en la guerra de España, Historia del Presente, ${ }^{\circ}$ 12, Madrid: Editorial Eneida, 2008/2, http://hdl.handle.net/10481/ 46192.

La ayuda Argentina a la República española. Un análisis a través del ejemplo marplatense, 1939, Congreso la Guerra Civil española, 1936-1939, Santos Julià Coord. Madrid: Sociedad Estatal de Conmemoraciones Culturales, 2007.

La República Argentina: el debate sobre la guerra civil y la inmigración, iAy de los vencidos! El exilio y los países de acogida. Madrid: Eneida, 2009, http:// hdl.handle.net/10481/45831.

El Fin de la Guerra Civil española y el exilio republicano: visiones y prácticas de la sociedad argentina a través de la prensa. El caso de Mar del Plata, 1939. Lleida: Universidad de Lleida, 2012, http://www.tdx.cat/handle/10803/83641.

CURREA-LUGO, Víctor De. América Latina y la Guerra Civil española. Madrid: Foro por la Memoria, 15 de enero de 2004, http://www.foroporlamemoria.info/ documentos/040114correa.pdf.

DEVOTO, Fernando. El revés de la trama: políticas migratorias y prácticas administrativas en la Argentina (1919-1949), Desarrollo Económico. Revista de Ciencias Sociales vol. 41, no 162, 2001.

MONTENEGRO, Silvina. La Guerra Civil española y la política argentina. Madrid: Universidad Complutense de Madrid, 2002, http://biblioteca.ucm.es/tesis/ghi/ ucm-t26475.pdf.

ORTUÑO MARTÍNEZ, Bárbara. El exilio y la emigración de posguerra en Buenos Aires, 1936-1956. Alicante: Universidad de Alicante. 2010, http://rua.ua.es/ dspace/bitstream/10045/20062/1/Tesis_ortuno.pdf.

PASOLINI, Ricardo. Intelectuales antifascistas y comunismo durante la década de 1930. Un recorrido posible: entre Buenos Aires y Tandil, Estudios Sociales. Vol. 26, $\mathrm{n}^{\circ}$ 1, 2004, https://bibliotecavirtual.unl.edu.ar/ojs/index.php/ EstudiosSociales/article/viewFile/2528/3602.

QUIJADA MAURIÑO, Mónica. Aires de República, aires de cruzada: la Guerra Civil española en Argentina. Barcelona: Sendai Ediciones, 1991.

RAPOPORT, Mario. Argentina y la Segunda Guerra Mundial: mitos y realidades, Estudios Interdisciplinarios de América Latina y el Caribe Vol. 6, n 1, 1995, http://eial.tau.ac.il/index.php/eial/article/view/1202/1230. 


\section{Lidia Bocanegra Barbecho}

RUBIO, Javier. La emigración de la guerra civil de 1936-1939: historia del éxodo que se produce con el fin de la II República española. Madrid: San Martín, 1977.

SCHWARZSTEIN, Dora. Actores sociales y política inmigratoria en la Argentina. La llegada de los republicanos españoles, Estudios Migratorios Latinoamericanos; n 37, diciembre 1997, http://clio.rediris.es/exilio/argentina/exilio_argentina.htm.

. Entre Franco y Perón. Memoria e identidad del exilio republicano español en Argentina. Madrid: Ed. Crítica, 2001a.

. Migración, Refugio y exilio: categorías, prácticas y representaciones, Estudios Migratorios Latinoamericanos, $\mathrm{n}^{\circ}$ 48, $2001 \mathrm{~b}$.

SENKMAN, Leonardo. La Argentina neutral de 1940 ante los refugiados españoles y judíos, Ciclos en la Historia, la Economía y la Sociedad. Vol. V, nº 9, 2do. Semestre 1995.

SPITTA, Arnold. Corrientes antisemitas y política de inmigración en la Argentina de los años treinta y cuarenta, Estudios Migratorios Latinoamericanos, $\mathrm{n}^{\circ} 11$, Abril 1989. 